\title{
Una visión real de la situación de la educación en El Salvador
}

OPINIÓN

Artículo escrito especialmente para la revista entorno, de la Universidad Tecnológica de El Salvador

Eduardo Badía-Serra

Recibido: 03/03/2014 - Aceptado: 23/04/2014

\section{Resumen}

La educación es el pilar fundamental de todas las sociedades. El progreso humano ha dependido siempre del desarrollo educativo; y la cultura, que no es otra cosa sino la historia reflejada en los propios actos de los hombres, se asienta en los valores y en los principios, así como en los conocimientos con que dichas culturas se han enriquecido. Es importante, pues, hablar de educación, preocuparse por la educación, pero ello, para que sea positivo y productivo, exige que el discurso y la preocupación se hagan con sanidad de conciencia, lealmente, honestamente, rigurosamente también, lo que significa evitar definitivamente la falsedad y el engaño. Desde estas premisas intento este pequeño aporte a entorno. Espero que el lector, de quien aprecio anticipadamente el que se ocupe de aquel, así lo crea y entienda.

\section{Palabras clave}

Desarrollo educativo, planificación educativa, modelos de enseñanza, desarrollo curricular, reforma educativa, educación y desarrollo, educación-El Salvador.

\section{Abstract}

Education is the cornerstone of every society. Human progress has always depended on the educational development; and culture, which is nothing but the history reflected in the actions of the men themselves, is based on values and principles, and in the knowledge that these cultures have been enriched. It is therefore important to discuss education, care about education, but that, to be positive and productive, requires that the discourse and concern do with health consciousness, loyally, honestly, rigorously also, which means definitely avoid falsehood and deceit. From these premises I try this small contribution to environment. I hope that the reader, who appreciate the advance to deal with that and believe and understand.

\section{Keywords}

Educational development, educational planning, models of teaching, curriculum development, education reform, education and development, education, El Salvador.

Eduardo Badía Serra. Doctor en Filosofía e Historia de la Ciencia, Instituto de Altos Estudios Superiores, Universidad de León-UOC-Universidad de Barcelona, España. Doctor en Química Industrial, Universidad de EI Salvador. Ingeniero Químico del Instituto Americano de Ingenieros Químicos, New York, USA. Licenciado en Filosofía Universidad Centroamericana "José Simeón Cañas". Fungió como Viceministro de Educación en el Ministerio de Educación de la República de El Salvador. 


\section{Una explicación necesaria}

La revista entorno, de la Universidad Tecnológica de El Salvador, me ha solicitado un artículo para uno de sus números monográficos, cuyo tema será la educación nacional. Con mucho gusto he aceptado tal solicitud, y he procedido a preparar dicho artículo bajo el nombre que se señala en su comienzo.

He pensado mucho sobre el carácter y la orientación que debiera dar al artículo en mención, y, ante la opción de presentar una visión en la que sean las estadísticas las que hablen, saturando al lector de datos y casos que, lejos de ayudar a lograr una visión clara de la situación, la confunden y oscurecen, estilo este por cierto muy utilizado en este tipo de labor, he optado por exponer, de una manera franca e inmediata, casi coloquial —diría yo—, mi visión acerca de la situación educativa del país; sobre la base de mi propia experiencia en las aulas y en los entornos educativos, enriquecida luego con mi participación en la gestión que, como viceministro de Educación del país, desarrollé a partir del 1 de junio del año 2009 hasta el 31 de enero del año 2012.

Considero que es oportuna esta aclaración, para que el lector pueda entender mejor mi posición. Por supuesto que en algunos momentos he recurrido a información y datos que he considerado necesarios, tratando en lo posible de referirme, en cuanto a estos últimos, de órdenes de cifras y no de cifras absolutas, cuestión que en ningún momento desfigura o hace perder validez al concepto que con ellos se trata de expresar o ampliar.

\section{La situación y el problema en una palabra}

En todos los contextos, en todas las situaciones, en todas las oportunidades, los salvadoreños sabemos expresar nuestra desaprobación a la situación del sistema educativo nacional. Los resultados de las mediciones que se hacen, y, sobre todo, la percepción, real por lo cotidiana y personal, de dicha situación, respaldan y justifican tal expresión. La situación de la educación en El Salvador no es todo lo deseable que debiera ser. Efectivamente, un sistema que se desarrolla desde un concepto pedagógico desfasado en el tiempo, sin pertinencia, en condiciones precarias de funcionamiento, y dentro de un entorno no lo más adecuado precisamente para su desenvolvimiento, no podría, de ninguna manera, producir resultados felices. El sistema educativo nacional, desde hace, por lo menos, cuatro décadas, viene producien- do resultados deficientes, que se reflejan en una condición de muy bajo nivel de educación en los ciudadanos. Aunque saben criticarse desde diferentes argumentos, crítica que más bien busca en el fondo justificar de alguna manera los malos resultados de la gestión educativa, mediatizando sus resultados, los datos que presenta la prueba Paes desde que esta se viene haciendo confirman tal situación.

Desde la primera "reforma" al sistema educativo que provoca la llegada del llamado "Plan Decenal" hasta su continuación con el "Plan 2021", muchos cambios se han producido en el diseño de planes y programas; pero muy poco estos se han reflejado en el aula, que es, en última instancia, en donde se debieran concretar. Una limitante de tales programas es que estos han sido introducidos desde diseños foráneos, concebidos en gabinetes de instituciones internacionales que para nada han considerado el entorno y la real condición del terreno en que deberían ser ejecutados. Si algo ha caracterizado a nuestro sistema educativo nacional es que se nos ha dicho, repetidamente, hasta la saciedad, vastamente, e incluso groseramente, lo que debemos enseñar y cómo lo debemos enseñar. Hasta el "Plan 2021", los salvadoreños no hemos podido, autónomamente, decidir tales cuestiones, otros han decidido por nosotros, y los resultados — vale repetirlo — han sido lamentables. Ello ha llevado al Ministerio de Educación a un estado de burocratización tal que los recursos se dilapidan en gestiones que no se justifican ni abonan al desarrollo de sus fines y objetivos. Un 'teoricismo' excesivo y una tendencia al control y a la evaluación rampante son reflejos reales de lo anterior. La evaluación ha dejado de ser un instrumento de medición, un medio, para expresar la condición del sistema, para convertirse en un fin en sí mismo. Y mientras el aula se debate en un esfuerzo precario y difícil, desde el ambiente hasta sus propias condiciones, los teóricos del Ministerio producen y producen documentos y propuestas alejados completamente de la realidad en la que deberán ser ejecutados.

Para poder, entonces, expresar realmente cuál es la condición del sistema educativo nacional hay, pues, que partir del reconocimiento de una premisa de carácter general, universal:

El sistema educativo nacional no está dando los resultados que debería dar, y la educación de la población, lejos de mejorar, muestra una tendencia creciente y continua hacia el deterioro, o al menos hacia la consolidación de su deficiente condición. 


\section{El problema de fondo}

Hay, pues, que buscar una respuesta a la situación que se plantea, una respuesta que vaya a su causa misma, y que conociéndola la solucione adecuadamente. Hay que identificar el problema, el problema de fondo, en su raíz. El problema de la educación nacional no es unicausal, sino multicausal, estructural, entonces. Tal razonamiento suele ser una especie de frase hecha, esgrimida cuando no se tiene la capacidad necesaria para llegar a una solución. Es, simplemente, una excusa, una forma de evadir el problema. $Y$ sobre esa base se suelen identificar muchas de esas causas, que, sin decir que no son reales, no son las principales, e incluso no son la principal. Suele hablarse del escaso financiamiento, de nuestra pobre inversión en educación; suele hablarse de la precaria situación de la infraestructura escolar; y así, del problema metodológico; de la falta de una propuesta pedagógica; de la muy baja formación de los docentes, etc.; temas a los que me referiré posteriormente.

Pero hay una causa, que es la principal, a la base de la cual se sitúa el problema, y sin cuya solución no puede resolverse. Esta causa nunca se esgrime en el discurso; nunca se expone en el discurso; no está en el discurso sobre la educación. Porque la educación, ciertamente, es parte del discurso político y de la expresión cotidiana de los estamentos superestructurales del Estado. Todos hablan de que a la base de todo está la educación. Sin educación no hay desarrollo, sin educación no hay progreso; sin educación no puede haber solución al problema económico; sin educación no se resuelve este coyuntural asunto de la delincuencia. Pero en el fondo, nadie se preocupa por la educación, sobre todo el Gobierno. Ciertamente, la educación ocupa el mayor porcentaje del presupuesto nacional, y cubre una razón importante del PIB nacional; pero ello es porque el gasto corriente así lo demanda. Hay que pagar, por supuesto, el salario a esa enorme masa de docentes que constituyen el cuerpo de maestros nacionales en el sistema público; $y$ hay que realizar el gasto que provoca el enorme aparato burocrático del Mined. Pero fuera de eso, nada, o muy, pero muy poco, queda para invertir en educación; en la mejora del sistema pedagógico; en la formación; el refrescamiento y la actualización der los maestros; en la mejora de sus condiciones de trabajo; en la optimización y actualización de la infraestructura escolar, pasando aquí por la racionalización del número de centros educativos, que es excesivo. El discurso ligero y superficial de los analistas y críticos del sistema educativo nacional siem- pre se centra en la necesidad de incrementar el gasto en educación hasta llevarlo al 607 \% del PIB nacional, cifra esa tomada de estándares internacionales o propuestas de gabinete que en nada se corresponden con nuestra realidad. Es — para decirlo con toda claridad - una especie de "receta de rabí". Incrementar el presupuesto nacional en educación hasta esos niveles significa algo así como duplicarlo; pasar de unos 800 u 850 millones de dólares anuales a unos 1.500 millones de dólares anuales. Esto es irreal si nos situamos dentro de nuestra nuda realidad económica y financiera. Y además, inconveniente; es provocar una mala señal, porque si bien, como premisa general, podemos decir que nunca los recursos para educar serán suficientes, hay que reconocer también que nunca será posible llegar a tal hipotética suficiencia, y además, que no solo se trata de gastar más, sino también de que lo que se gaste se gaste bien. Y eso es un poco lo que no ha sucedido en el país. El gasto en educación no ha sido hecho racionalmente, priorizando los problemas esenciales y dándole a ellos la mayor atención y dedicándoles el mayor esfuerzo económico. Aquí entra una variable que es preciso colocar a la luz de este razonamiento; y es la de los intereses políticos y de partidos.

El Salvador, actualmente, gasta unos 850 millones de dólares por año en educación, como presupuesto Goes. Si a esto le sumamos las ayudas externas, los préstamos, y otras aportaciones, el Mined maneja algo así como unos novecientos cincuenta millones de dólares anualmente en la educación pública. Sitúo cifras aproximadas, órdenes de cantidad, debido a que no dispongo al momento de las cifras exactas, pero aseguro que las que he situado se corresponden muy cercanamente con la realidad. La población estudiantil en el sector público es del orden de 1.7 millones de estudiantes, incluyendo la población en educación superior. De tal manera que el país gasta un promedio de 550 dólares por estudiante por año en educación pública, esto es, unos 55 dólares mensuales por estudiante. Esto, ciertamente, no es mucho; pero de la misma manera, ciertamente, no es poco si lo comparamos con el costo promedio de la educación privada, eliminando los términos extremos que en esta se dan para hacer confiable la medida de tendencia central expresada. Y, por mucho que esto se quiera desvirtuar, como viene siendo el intento de nuestras autoridades educativas últimamente, hay que reconocer que la educación privada - de nuevo eliminando los valores extremos para hacer consistente el dato- es, en todo sentido, de una superior calidad que la educación pública. 
Si abundamos un poco en algunos datos, con carácter muy general, podríamos conocer que, para una población del orden de 1.7 millones de estudiantes, el Mined dispone de aproximadamente 40 mil maestros, algo así como 42 estudiantes por maestro. Esto no representa una cifra óptima para el sistema pedagógico nuestro, pero tampoco es tan rechazable; y para un sistema pedagógico moderno, que tenga a su base el aula integrada, el grupo docente y la biblioteca especializada como parte del sistema, en sustitución de los ya anticuados y nada pertinentes conceptos del maestro único, del aula de grado y del de la biblioteca general, conceptos en los cuales permanecemos anclados aún, tal cifra es realmente pequeña, y significa una eficiencia en el uso del recurso docente muy baja.

El país cuenta con aproximadamente 6 mil escuelas o centros escolares. De nuevo, para una población estudiantil del orden de 1.7 millones de estudiantes, esto significa un promedio de población del orden de 280 estudiantes por escuela, lo cual, desde un concepto pedagógico moderno, es una cifra excesivamente baja; si a ello agregamos que de estas 6 mil escuelas, unas 2 mil funcionan con poblaciones menores de 100 estudiantes, muchas de ellas desde el concepto de maestro y aula múltiple, mezclando irracional y antipedagógicamente en una misma aula niños de diferentes edades y niveles de formación; concepto este perverso y nocivo para un adecuado desarrollo pedagógico; y si a lo anterior agregamos todavía que estas últimas funcionan predominantemente en "el campo", esto es, en el área rural, lo cual agudiza la realidad crítica y rechazable de que en el país la educación se estratifica en función de los diferentes estratos sociales, teniendo escuelas para pobres en el campo y escuelas para menos pobres en la ciudad, siendo la de los estratos pobres la de peor calidad, y negando aquel principio de que "es peor educar mal a un pobre que no educarlo", que tanto repiten los teóricos de los gabinetes de las instituciones internacionales; de nuevo llegamos a la conclusión de que hay un inadecuado uso de los recursos educativos, en desmedro de la posibilidad de prestación de una educación pertinente y de calidad. Existió, y existe aún, el prurito de "hacer" escuelas tanto más para salir en las fotografías y en los medios de comunicación. Hay que "hacer" escuelas para utilizar eso como recurso de propaganda. Por supuesto, después de "hechas", no hay problema en olvidarse de ellas y relegarlas a la peor condición imaginable. Esa era parte de la "política educativa nacional del Plan 2021", y por ello disponemos ahora de más escuelas que las necesarias, en condiciones deplorables la mayoría de ellas, y con diferencias sociales y geográficas realmente condenables. En el país tenemos centros educativos con poblaciones que oscilan entre los 35 y 40 estudiantes las más pequeñas, y los 5 a 6 mil las más grandes. Aquellos que saben hablar y defender el programa Educo -idea universal del Banco Mundial que lo único que vino a provocar es ahondar la brecha del conocimiento- deberían investigar un poco más en profundidad la realidad educativa en que funcionaba dicho programa, antes de opinar ligeramente.

No debemos cometer el error de pensar que la brecha del conocimiento se elimina regalando computadoras obsoletas a cada niño rural, porque eso nos llevaría a incurrir en un error probablemente más profundo que el que se cometió con el problema Educo, pues a aquel deberá entonces sumarse la promoción de un mayor estado de dependencia cultural.

El problema, entonces, no debe abordarse desde sus ramificaciones periféricas, sino yendo al centro de la cuestión. ¿Cómo es posible que tantos años de gestión, con tanto respaldo de asesores, consultores, especialistas, estudios, diagnósticos, y con una realidad que nos está mostrando diariamente en dónde se encuentran sus causas, no hayan sido suficientes para orientar el esfuerzo en atacar y resolver dichas causas?

El asunto es que el problema central tiene una raíz muy profunda y difícil, y es que

la educación no ha sido ni es, en realidad, una prioridad para nuestros gobiernos, sino solamente una herramienta demagógica de propaganda política partidaria.

Efectivamente, la educación es un recurso propagandístico de los gobiernos nacionales; es parte del discurso; es parte de esa expresión de fachada democrática de nuestros gobernantes. En el fondo no constituye, ni ha constituido, una verdadera prioridad en el hacer nacional. Este es el problema de fondo. Esta es la causa central de su deficiente estado. Y si nuestros gobernantes no llegan a asumir la educación verdaderamente como una prioridad, y esto, más aún, como la primera prioridad del hacer nacional — como saben afirmar en sus discursos-, el problema de la educación no podrá resolverse; lejos de eso, tenderá hacia su agudización 0 , al menos, hacia el sostenerse en tal estado. 
Siempre hay una crítica severa, de todos y por todos los rumbos, al estado de la calidad educativa. El morbo en torno a este punto se agudiza cuando se publican los resultados de la Paes. Y efectivamente, la calidad educativa nacional es precaria: no superamos el $6^{\circ}$ grado de nivel educativo nacional; no superamos el 6.0 de calificación en la nota de dicha prueba, aun aplicando las famosas "curvas"; las "paesitas" —otra ocurrencia de los rabís que nos vienen a dejar permanentemente sus recetas - dan como resultado niveles de calificación similares o inferiores a la Paes; la prueba Ecap, que es la prueba a la que se someten los futuros maestros, es, lamentablemente, siempre menor que 4.0; etc., etc. etc. El sistema tiene mucha parte de la culpa en lo anterior. Pero también, exigir a un maestro que enseñe en un ambiente nada propicio para el aprendizaje es una tarea poco menos que dantesca. Como suelo decir —y lo sostengo-, "la escuela no puede enseñar lo que la realidad niega". Además, ¿cómo lograr hacer eficiente un sistema en el que el líder de una escuela, el director, es cargado con una cantidad de tareas administrativas que le roban más de la mitad de su tiempo de trabajo, y para las cuales tiene que apoyarse además en uno o más maestros que debieran estar en el aula y no llenando formularios? ¿Cómo lograr que un maestro enseñe bien, si la mayor parte de su tiempo pasa organizando las labores de entrega del vaso de leche; de la merienda escolar; del filtro escolar; de la revisión de seguridad; de la repartición del paquete escolar; de los dos uniformes y del par de calzado? No es que quiera negar la conveniencia de que un niño asista a la escuela adecuadamente vestido, con sus útiles completos, con una buena alimentación, sano, y limpio de conciencia; pero alimentar a la población, vestir a la población, mantener una buena salud en la población, etc., no son precisamente labores que corresponden a la escuela o al Ministerio de Educación; y obligar a que este asuma tales compromisos es desviarlo, precisamente, de su propias funciones y de sus propios objetivos. Además, como tales labores no son las propias, normalmente se hacen mal, con poca eficiencia y con casi nula efectividad.

¿Cómo obligar a un maestro, entonces, a que enseñe con calidad, si la mayoría de su tiempo se le distrae en ocupaciones que no son las propias para provocar tal educación de calidad?

Volviendo al caso. Si estos temas no se enfocan con criterio sano y técnico, y más bien se enfocan bajo cargas políticas y de partidos, no podrán ser resueltos. Y ello no se hace así porque, simplemente, la educación — como he apuntado- no es, ni lo ha sido, una prioridad real para nuestros gobiernos, sino parte del discurso demagógico propio y característico de nuestra realidad. Lamentablemente, percibo que tal situación continuará en los próximos años.

El punto de partida, entonces, para resolver, de raíz, de fondo, y con seguridad, el problema educativo nacional es hacer que este se considere, realmente y no demagógicamente, como una prioridad, de la gestión de nuestros gobiernos. Si ello no es así, nunca, tal problema, tendrá una solución real y firme.

Principales obstáculos para un buen desarrollo educativo. Los objetivos del sistema: cobertura, calidad y pertinencia

Si, y solo si, partimos de la posibilidad de que pudiera resolverse lo que he dado en llamar "el problema de fondo" de la educación nacional, y se lograra entonces que nuestros gobiernos asumieran el hecho de que la educación está a la base de toda posibilidad de progreso, priorizando su desarrollo y dándole efectivamente el impulso necesario, abandonando la posición demagógica de utilizarla como un medio para la promoción política y partidaria, como ha sido hasta hoy desde hace por lo menos unas cuatro décadas; es decir, si se resolviera el problema político que obstaculiza y detiene su desarrollo, entonces habría que dimensionar y priorizar los verdaderos problemas por los que ahora atraviesa y enfocar las posibilidades de solución a los mismos.

Considero, desde tal hipótesis (cuya concreción veo, ciertamente, muy lejana y difícil, pero que puede asumirse como una hipótesis), que los siguientes problemas son los que se deben plantear y resolver:

1) El modelo de desarrollo y la visión del país que se quiere.

2) El modelo educativo.

3) La legislación educativa.

Y tales problemas deben considerarse bajo la perspectiva de que siempre habrá que fundarse sobre tres objetivos fundamentales:

a) Cobertura

b) Calidad

c) Pertinencia 
Estos tres elementos no pueden ser vistos separada e independientemente el uno del otro, cuestión que ha sido un error esencial en las gestiones educativas. Para que nuestros jóvenes reciban una formación integral, los tres factores arriba mencionados deben ser desarrollados considerándolos como un solo conjunto.

No puede haber calidad si la educación no es pertinente. La necesidad de educar para el aquí y el ahora es fundamental y absolutamente necesaria. No puede educarse a una población para que esta educación responda a otros contextos y a otras realidades. Solo una educación pertinente es una educación de calidad.

Por supuesto que la calidad no se agota en la pertinencia. La pertinencia es el elemento que da valor y pondera adecuadamente al conocimiento y a la formación, que son los otros elementos esenciales de la calidad. Para decirlo de otra manera: formación, conocimiento; y ambos elementos pertinentes, esto es, propios a nuestra realidad y adecuados a nuestras necesidades.

Aquí deseo remarcar una cuestión que es de medular importancia, y cuya equivocada interpretación puede llevar a un lamentable y no enmendable error. No debe confundirse conocimiento con información. Cuando hablamos de una educación de calidad, refiriéndonos al factor conocimiento, hablamos de formar una sociedad del conocimiento, que es algo medularmente diferente de lo que es una sociedad de la información. Una sociedad informada solo es autónoma, libre, legítima, si es una sociedad del conocimiento; pero una sociedad informada, si no está adecuadamente formada y si no tiene un adecuado conocimiento de la ciencia y de la técnica universal, viene a ser una sociedad propicia a la esclavitud, heterónoma, ilegítima, tanto más cuanto si es una sociedad que no produce información y menos aún conocimiento, sino solo los recibe. Lógicamente, será una sociedad informada $-\mathrm{y}$ lo más que se quiera-, pero de aquello de lo que los que informan nos quieran informar. Esto es peligroso, es un signo vital de un estado de dependencia, proclive al servilismo.
La computadora en el aula es - puedo afirmar esto con absoluta propiedad-, un elemento que, si no se ubica en el contexto adecuado, puede constituirse en un elemento deformante para el joven; esto, más, si tal computadora es un modelo atrasado, un juguete en manos de un niño que no lo puede utilizar adecuadamente.

A lo anterior se suma otro error conceptual que se viene manejando equivocadamente en nuestro ambiente educativo: la tendencia a reducir la tecnología y la ciencia a la informática y su mundo. Este es un error de crasa ignorancia. La informática es un medio, un medio técnico ciertamente, para desarrollase adecuadamente en la ciencia y en la tecnología; pero estas no se confunden con ni se reducen a ella.

El otro aspecto es el de la cobertura. Ciertamente, hay que educar a todos, porque la educación ilumina. Pero con el afán de que nadie se quede sin ir a la escuela, no se justifica educar a todos deficientemente. Como ya he dicho anteriormente, es peor educar mal a un pobre que no educarlo; y siendo nosotros, los salvadoreños, pobres, es un delito lamentable y castigable duramente el que estemos educando mal a nuestros niños y a nuestros jóvenes. Enviar al niño a la escuela con el solo afán de llenar una aspiración estadística de matrícula es lamentablemente un irrespeto al derecho de ese niño, si ello no se acompaña de la seguridad de que al enviarlo se situará en un ambiente educativo; en un contexto educativo y bajo un modelo educativo que lo educará con calidad y con pertinencia — vale decir— para la vida.

No debe confundirse la cobertura con la masificación; la cobertura es, más bien, la aspiración a la universalización del conocimiento. Hay que educar para la vida. Si no se educa para la vida, la educación pierde su razón de ser.

Los modelos educativos en uso en el país, desactualizados y desinformados de las realidades mundiales, se hacen siempre la pregunta: ¿qué enseñar? Por ello, sus teóricos se envuelven en la trama oscura de los famosos diseños curriculares y sus correspondientes elementos punitivos, los elementos de evaluación. Se trata de enseñarlo todo, abso- 
lutamente todo, sin dejar de incluir nada en los programas; y luego, hay que evaluarlo todo: al estudiante, al maestro, al coordinador, al director, al edificio en donde funciona la escuela, a la familia, a la comunidad y a la sociedad misma. Esto no es lo que actualmente se busca al educar. Ahora, las preguntas primeras son: ¿por qué enseñar?, ¿para qué enseñar? Solo previamente resuelto o respondido esto, puede llegarse correctamente a lo otro. Solo si sabemos por qué enseñamos y para qué enseñamos podremos dar una respuesta adecuada al qué debemos enseñar y cómo nos debemos evaluar. Los salvadoreños, sobre todo los de hoy, solemos colocar la carreta antes que los bueyes; esto es un problema. Solo si sabemos para qué y porqué educar estaremos educando para la vida, que es, con todo, la razón de ser, el fin último, de todo sistema educativo. Si no nos educamos para la vida, ¿para qué nos educamos?

\section{El "Plan Social-Educativo 2009-2014 'Vamos a la escuela' ".}

La gestión del Ministerio de Educación, al comienzo del actual gobierno, luego de un elaborado diagnóstico de la situación de la educación nacional, hizo una nueva propuesta. Esta se contuvo en el "Plan Social-Educativo 2009-2014 'Vamos a la Escuela' ", con su modelo de "Escuela Inclusiva de Tiempo Pleno" y sus estrategias de "Nuclearización Escolar" y "Administración Escolar". Este tuvo un apoyo sin precedentes dentro del sector docente y de la cooperación internacional. Los maestros nacionales vieron en la propuesta y el modelo la alternativa que se había por tanto tiempo buscado. La cooperación internacional apoyó denodadamente el esfuerzo. La cooperación italiana brindó ayuda económica y técnica de muy alta calificación, con el apoyo de la Universidad de Bologna, al desarrollo del modelo pedagógico de la Escuela Inclusiva de Tiempo Pleno; la cooperación española respaldó fuertemente el esfuerzo de actualización, refrescamiento y especialización docente, y la formación del Instituto Especializado Escuela Superior de Maestros, viejo anhelo de los maestros después de desaparecidas las antiguas escuelas normales; AID apoyó el esfuerzo de nuclearización escolar; $y$, finalmente, el Banco Mundial otorgo un préstamo de 60 millones de dólares orientado al desarrollo y la consolidación del modelo.

Se hizo una profusa distribución de documentos de trabajo y de estudio; se desarrollaron numerosas jornadas de difusión y consulta; se establecieron los proyectos pilotos, como una ventana de demostración de lo que era la idea de la nueva escuela. El proyecto, fuertemente difundido, no fue, sin embargo, bien recibido. Las resistencias llegaron desde el interior mismo del Ministerio de Educación, donde vieron en el plan y en el modelo un obstáculo al trabajo territorial; y además, desde la oposición política, la que intuía un rompimiento con los anteriores modelos contenidos en el Plan Decenal y en el Plan 2021. Muchos analistas políticos y educativos - acostumbrados a ser los referentes en todo proceso educativo y a ser siempre considerados en su elaboración y consultados antes de su implantación- se sintieron relegados en este nuevo esfuerzo y presentaron su oposición. El "Plan Social-Educativo 2009-2014 'Vamos a la Escuela' ", el modelo de "Escuela Inclusiva de Tiempo Pleno", y sus estrategias de nuclearización escolar y el nuevo sistema de administración escolar, comenzaron entonces, si bien con mucho apoyo en lo niveles docentes y de la cooperación internacional, con muchas resistencias en el entorno propio en el que se desarrollaría. Esto último tanto en el ámbito político como personal. Su ejecución fue muy difícil. Y después de dos años y siete meses de esfuerzo inicial, dichos plan y modelo comenzaron a ser progresivamente desnaturalizados, negando su rico concepto pedagógico y dificultando su ejecución.

El intenso trabajo ejecutado en la búsqueda de provocar las condiciones adecuadas para el desarrollo del plan y su modelo hizo que quedaran listos importantes documentos, entre los cuales señalo:

1) nuevas propuestas de leyes general de educación, de educación superior y de la carrera docente;

2) nuevas propuestas de planes y programas de estudios para la formación inicial de maestros;

3) creación del Instituto Especializado Escuela Superior de Maestros, Esma;

4) programa de refrescamiento, actualización y especialización para maestros en servicio; $y$

5) plan de desarrollo del modelo de Escuela Inclusiva de Tiempo Pleno, con su respectivo financiamiento a siete años plazo.

En mi opinión, siempre he considerado que esta nueva propuesta educativa nacional representaba un fuerte cambio en el sistema, con posibilidades reales de mejora en los aspectos más deficitarios de la educación, especialmente aquellos que corresponden a una educación de calidad y con pertinencia, a la superación del nivel nacional de esco- 
laridad, y a la universalización de la cobertura. Por otro lado, siempre consideré que

la Escuela Inclusiva de Tiempo Pleno era la forma culta y efectiva de combate a la inseguridad y a la delincuencia en las escuelas; de la superación de la deserción escolar, y del abatimiento de los niveles de reprobación y repitencia.

Creo que, lamentablemente, esto no logró ser comprendido por quienes tienen esa seria responsabilidad de dirigir nuestra educación; e insisto en situar esta incomprensión en el hecho de que, para ellos, en el fondo, en la realidad, la educación del pueblo no es una prioridad.

\section{El modelo de "Escuela Inclusiva de Tiempo Pleno"}

Quisiera finalizar este trabajo hablando un poco de lo que son el "Plan Social Educativo 2009-2014 'Vamos a la Escuela' " y su modelo de "Escuela Inclusiva de Tiempo Pleno". No es posible en un espacio tan reducido poder describir y exponer a cabalidad ambos proyectos. Solo intento resumidamente colocar los elementos medulares de ambos.

La Escuela Inclusiva de Tiempo Pleno no es el simple alargamiento de una jornada escolar, acompañada de vasos de leche $y$ de desayunos escolares. Es una reforma que va a los cimientos mismos del sistema educativo, que lo transforma severamente, y que lo coloca en el concierto de los mejores programas educativos a escala mundial.

La Escuela Inclusiva de Tiempo Pleno no es un sistema ni un plan. Es más bien, una idea, un concepto. Por tanto, su espacio está en las mentes de quienes en ella participan. En esas mentes se anclan sus postulados, y, una vez anclados, no hay posibilidad alguna de que sean removidos o sustituidos.

La Escuela Inclusiva de Tiempo Pleno busca, antes que informar, formar: formar una sociedad del conocimiento, en la que la información es solo un componente, importante ciertamente pero no esencial; un medio para consolidar la formación, que es su propósito principal.
Por ello, la Escuela Inclusiva de Tiempo Pleno es la forma efectiva de combatir ese flagelo que abate a nuestra sociedad, que Veggeti Finzi muy bien ha llamado "familia presurosa", porque busca integrar en la escuela los diferentes estamentos de la sociedad, haciendo que en ella se encuentre la adecuada relación entre la propuesta de enseñanza y la vida misma. Es, pues, educar para la vida. Cuando decimos 'Vamos a la Escuela' estamos tratando de decir que a la escuela deben ir los niños, los jóvenes, los maestros, los administradores escolares, la familia, la comunidad y la sociedad misma, en un espacio abierto y continuo en el cual no hay paredes que la limitan ni tiempos que la estrechan.

¿Qué son el "Plan Social-Educativo 2009-2014 'Vamos a la Escuela" " y el modelo de "Escuela Inclusiva de Tiempo Pleno"?

Intento una muy resumida exposición:

1) Fundamentación de la necesidad del cambio en el modelo educativo nacional

El desarrollo del mundo actual $-\mathrm{y}$ seguramente del mundo futuro próximo- exige una reflexión sobre lo que deben ser las relaciones entre el conocimiento y la familia en la sociedad, a fin de que los esfuerzos y la responsabilidad del individuo en una realidad que cambia puedan ser valorados conscientemente. Una reflexión necesaria, esta, que llevaría, sin duda, si se actúa responsablemente, a proponer una política educacional moderna, modificando los criterios y los métodos tradicionales de aprendizaje, y cambiándolos por unos que desarrollen la creatividad humana mediante una adecuada formación y preparación de los jóvenes en la gestión cultural del cambio en la acción.

Si algo está ahora en el centro de la discusión de los problemas esenciales de la humanidad es el papel de la escuela; y no hay lugar para la duda en cuanto a que la escuela tradicional no soporta el reto que le impone la nueva realidad, que se va revelando en el albor de este nuevo siglo. 
No es, pues, la necesidad del cambio educativo el que debe discutirse, sino más bien cuál debe ser ese cambio y a qué papel lleva este al hombre dentro de su misma sociedad y del ámbito mundial. Es necesario modificar el diseño de la escuela; y es necesario, además, modificar el diseño del aula misma. Para ello, se impone reconocer cuáles son las causas que impelen al cambio y cómo y en qué intensidad se manifiestan. Y como estas causas y sus respectivas intensidades surgen de la realidad concreta de los pueblos, es necesario entonces ir a esas realidades y conocerlas, para que los cambios sean orientados y direccionados en función de ellas.

El intelectual salvadoreño Alejandro Dagoberto Marroquín anotaba lo anterior ya hace más de medio siglo cuando decía: "El papel de la educación adquiere, en este mundo, relieves trascendentales; la educación orienta, forma y despeja horizontes con vivas perspectivas, ayuda a conquistar seguridad y firmeza. Pero ante la emergencia crítica que confrontamos se impone reorientar la política educativa a fin de que comprenda y asimile las nuevas circunstancias". De ahí surge como primera necesidad el imperativo de conocer plenamente la realidad actual, pues, evidentemente, para actuar sobre una realidad; es necesario conocerla previamente. Nada nuevo, entonces. No hay realidades estáticas y, menos, eternas; cambian las circunstancias, y consecuentemente deben cambiar las formas en que estas circunstancias deben ser enfocadas. Es un poco como tejer y destejer el manto de Penélope.

Los elementos más evidentes de la sociedad mundial en este momento son los de la globalización y de los cambios continuos y rapidísimos en los niveles económico, social, de la información, de la comunicación y de la tecnología que dentro de ella se están dando. Estamos ante una sociedad del cambio; y ello coloca a los sistemas educativos frente a nuevas posibilidades y problemas dramáticos. Estamos ante una sociedad que enfrenta, sin razón, al conocimiento con el progreso y el bienestar económico, identificándolos como opuestos. Y, al mismo tiempo, reconocemos un crudo incremento en las desigualdades sociales; en la proliferación de las guerras, y en el desorden ecológico a escala planetaria. La tarea que compete, pues, a la educación es evidente y está llamada a medirse con estos nuevos desafíos.
La globalización, tanto económica como cultural, coloca a la escuela tradicional en el centro de la discusión. Como siempre, el deber del sistema formativo debe enfocarse viendo al pasado, viendo al presente $y$ viendo al futuro. Debe verse al pasado porque es necesario proteger y sostener el patrimonio cultural, la diversidad dentro de esa totalidad abarcadora en que se vive en el mundo. Las nuevas generaciones -imperativo categóricodeben reconocerse en las pasadas, a riesgo de no hacerlo y caer en manos de la dependencia. Es ahí donde se funda y refunda el sentido de pertenencia a una comunidad, se favorece el desarrollo de la propia identidad y se alimenta la dimensión ciudadana.

Pero, ¿cómo concebir tal empeño hoy, en una realidad de acentuado pluralismo cultural? Las historias locales se mezclan con las otras historias; las propias tradiciones con las otras tradiciones; $y$ si antes las aldeas podían considerarse mundos, hoy es el mundo el que se ha convertido en una aldea, mutiétnica, multireligiosa, multicultural. ¿Cuáles son las posibles actitudes que se podrían tomar? La una, cerrarse, ante el miedo al otro y el temor a perder la propia identidad; la otra, el insertarse en la globalización de una forma acrítica, dejándose homologar en una masificación cultural que niega toda identidad.

Toca a la educación decidir en ese contraste radical de posibilidades; entre el localismo de la patria pequeña y la masificación homologante. Ser ciudadanos del mundo como apuntaban ya hace más de dos siglos los estoicos aquellos—, o ser ciudadanos de la villa local; la aldea global o la aldea local; abrirse con el peligro de ignorarse a sí mismo; o cerrarse, identificados pero ignorados. ¿Quién decide? La escuela. La educación. El sistema educativo.

El segundo desafío guarda la dimensión del futuro. A la escuela de cada tiempo le toca preparar al joven de cada tiempo, para que se inserte en la vida social con las competencias y los conocimientos necesarios para que tal inserción sea adecuada. 
También esta tarea requiere ser repensada, porque los cambios velocísimos y profundos que a cada nivel se suceden hoy en el mundo, tanto en lo social como en lo económico, político y cultural, vuelven fácilmente obsoleto todo aquello que en la escuela se enseña.

No sería nada nuevo decir que la escuela debe ser un lugar en el cual se enseñe a vivir con sí mismo y con los otros. Pero la escuela debe ser algo más: el punto en el que se identifican plenamente la familia y la sociedad. Una escuela aislada de sus comunidades, e incluso de las mismas familias, no puede dar buenos resultados, y, más que eso, deberá calificarse como una escuela de suyo deformante. Ahora nos encontramos ante una realidad en la cual los jóvenes son depositados por los padres abrumadora y tempranamente. Estamos ante el mundo de las "guarderías", en donde los pequeños seres son "guardados" por sus padres, mientras estos resuelven su vida; estamos ante el mundo de las "parvularias", donde los párvulos son también dejados al cuido de unas madres que no tienen leche materna. Esa es una realidad, golpeante y dura, que relativiza los sentidos del afecto y del amor que van fijándose en el ser desde que abandona el vientre.

A ello se suma el relativismo hacia todo. Ya no hay verdades; ya no existen visiones únicas del mundo; ya no estamos ante el mundo de la razón, sino de lo simbólico y de la realidad mediática. El mundo es como lo ve cada quien, y, con ello, hay siete mil millones de tales visiones. Ante esa realidad, la escuela requiere cambiar para adecuarse a lo que quieren y necesitan los jóvenes; para adecuarse críticamente a la globalización, y para adecuarse a los cambios rápidos que se dan en el mundo en todos los órdenes y en todos los sentidos.

Ciertamente —como decía Einstein- "...solo puede vivirse la vida a una velocidad de una hora por hora"; pero ciertamente, iqué rápidas parecen avanzar las horas en estas vidas que vivimos! Globalización, cambio y nueva realidad juvenil. Eso es lo que obliga a una nueva escuela.

Y la nueva escuela, para decirlo en una sola palabra, lo que debe hacer es "encontrar la adecuada relación entre la propuesta de enseñanza y la vida misma".

\section{2) La nueva escuela. El rediseño del aula}

He sentido, entonces, que es necesario redefinir la escuela, redefinir el aula; rediseñar la escuela; rediseñar el aula. Normalmente, los esfuerzos han estado siempre encaminados hacia la reforma de los contenidos de las asignaturas y de las formas y métodos de evaluación. Es la famosa y estéril "reforma curricular". Sin negar que lo anterior es siempre una actividad que debe desarrollarse con carácter permanente, en la realidad, lo que debe reformarse, cambiarse, rediseñarse, es el concepto mismo de escuela, y con ello, el concepto mismo de aula. Siempre los contenidos deberán ser actuales, con la profundidad necesaria y adecuadamente organizados, y escalados. Pero el problema no reside en ello, sino más bien en la forma en que son abordados, para que el estudiante los asimile en la mejor forma posible.

¿Qué debe entenderse por rediseñar la escuela, por rediseñar el aula? Un rediseño de la escuela, para adecuarla a las necesidades de la época y del futuro que se espera, significa:

a Sustituir el viejo concepto de enseñanza por materias, por el de enseñanza por disciplinas. Esta diferencia entre materia y disciplina es sutil, pero es importante. Por materia se entiende el conjunto de contenidos presentes en un determinado campo. Por ejemplo, los contenidos de la historia son los datos del hombre mismo suspendido en el tiempo; los de la geografía, la naturaleza y la organización de los diversos paisajes. Por disciplina, en cambio, no debe solo comprenderse los diversos contenidos, sino también la metodología, que regula el funcionamiento; los procedimientos que se deben seguir para resolver los diferentes problemas que abren los proyectos de investigación, y poder procurarse así la información necesaria. La materia escolástica es así sustituida por la disciplina de estudio.

b) Sustituir el concepto de maestro de grado por el de grupo docente. Decir "la escuela" es, todavía hoy, decir "el maestro", justamente en el sentido del maestro único. A pesar de que este paso es de suyo muy delicado, ello debe hacerse en la plena conciencia de que no se trata de reunir un grupo heterogéneo sin organización alguna, sino de constituir un grupo que en 
la diversidad y en la especificidad de sus aportes individuales sea capaz de desarrollar un proyecto educativodidáctico fuertemente unitario.

c) Acercar al alumno a su contexto de vida, en vez de someterlo a un programa centralizado uniforme. La lección tradicional debe ceder el puesto a la metodología de la investigación; el programa centralizado uniforme debe ser sustituido por un acercamiento no espontáneo, pero sí más atento a las exigencias del alumno, considerado este en el concreto de su contexto de vida.

d) Provocar el desarrollo de una escuela de la investigación en sustitución de la escuela de las nociones $y$ de las lecciones. Hay que superar la escuela de las lecciones, la escuela de las nociones, y ello es posible fundando la didáctica sobre sólidas bases científicas. El alumno debe transformarse en el justo protagonista de su propia formación. La investigación se contrapone a la lección, el alumno es el protagonista, y el profesor, aquél que lo acompaña y estimula.

e) Y, lo más importante aquí, conformar una escuela de "tiempo pleno". No se trata ya de sostener una escuela de tiempo parcial a la cual se asocien experiencias insuficientes ligadas a acciones asistenciales, más que pedagógicas, dedicadas a acoger alumnos con variadas necesidades, pero sin constituir un verdadero enriquecimiento de la oferta formativa. La escuela de tiempo pleno constituye un modelo capaz de integrar, en una propuesta curricular homogénea, una misma calidad formativa para todos. A la escuela actual, de una frecuencia del orden de 25 horas semanales y de la presencia del maestro único de clase, se opone una nueva escuela de frecuencia semanal de 40 horas y atendida por grupos docentes en vez de maestros únicos. La dimensión relativa a la organización complexiva del tiempo pleno (en la escuela tradicional, clasemerienda-clase) obliga a una programación de una jornada mucho más prolongada, en la cual se combinan metódica y orgánicamente los espacios de trabajo de grupo, las pausas, los espacios reservados al desarrollo y a la iniciativa personal, el tiempo de la recreación y el juego.
La dimensión didáctica requiere la colaboración de todos; y la presencia de los grupos docentes crea las condiciones para una mejor distribución de las tareas. Se activan varias modalidades de reagrupamiento de los estudiantes en relación con las diversas actividades y proyectos; y los diferentes miembros de los grupos docentes comienzan a especializarse, dedicándose progresivamente a una específica disciplina. En la mayoría de casos, el libro de texto es considerado inadecuado y se prefiere elegir como modalidad didáctica la biblioteca de trabajo, con metodologías que apuntan a la práctica de la investigación, del laboratorio y de la animación experimental.

Se trata de reducir el tiempo obligatorio dedicado al común para todos los estudiantes, permitiendo una cuota facultativa de actividades educativas seleccionadas libremente por los alumnos y por las familias (enriquecimiento formativo opcional, laboratorios personales, experiencias externas, aprendizaje informal, etc.). Como un efecto colateral, se tendría una mayor flexibilidad de los recursos formativos, interpretados ya no más dentro de los términos rígidamente escolásticos, sino en sintonía con el principio de una mayor personalización del aprendizaje.

Con la escuela de tiempo pleno se busca dar cumplimiento al derecho al estudio y, consecuentemente, a la instrucción a las que tienen todos los ciudadanos; se busca una relación más plena con la comunidad, con la cultura, con el territorio; se adquieren y reafirman valores de respeto a la diversidad, a la identidad, a los elementos raciales; se proyecta un horizonte más vasto mediante el poder del conocimiento, de una instrucción que emancipa y libera.

Un rediseño del aula, por su lado, implica:

\section{a) Sustituir la lección del catedrático por la biblioteca} de trabajo. A la pedagogía del manual, de la lección del catedrático, del voto que discrimina y selecciona se contrapone una pedagogía alternativa y una didáctica nueva, que promueve el protagonismo del estudiante, su participación, el aprendizaje activo. Debe superarse el libro de texto por la biblioteca de trabajo, mucho más rica en aportes de lo que pueda serlo un genérico manual escolástico. La biblioteca de trabajo puede comprender revistas, enciclopedias, libros de varios tipos, material audiovisual, programas computaciona- 
les, pizarrones virtuales, visitas de campo, experiencias demostrativas, etc.

b) Sustituir la pedagogía del manual por una pedagogía alternativa, en conjunción con lo anterior. ¿Qué se busca con la pedagogía alternativa? Disponer de espacios de reflexión entre los actores del proceso, que permitan un diálogo directo en el que se aborden los diferentes temas con un sentido abierto y dispuesto a desaprender y reaprender el conocimiento, acercándosele desde el contexto que lo rodea, en forma tal que el alumno sea el propio protagonista de su proceso formativo, orientado y guiado por el grupo docente, y alimentado y fortalecido con el apoyo de la familia y de la comunidad. Hay, pues, una apertura al territorio no casual, sino orgánicamente programada; hay también una relación constante de comunicación y diálogo constructivo con la familia; hay una actitud de investigación continua desarrollada por maestros y estudiantes con la contribución de la familia y la comunidad en el entorno mismo del propio contexto de vida.

c) Conformar un aula integrada en la cual puedan interactuar organizadamente todos los actores: alumnos, grupos docentes, recursos didácticos y pedagógicos, etc.

Esta aula debe modificar su contextura y su organización, así como las formas en que los agentes en ella interactúan, en función de los diferentes niveles a los que vaya accediendo el estudiante.

\section{3) La escuela como núcleo de cultura}

La cultura se da en la historia, es un producto de la historia. Y la historia se concreta en la cotidianidad del pasado reflejada y registrada en los hechos del presente. Una educación solo tiene validez si es pertinente, y solo es pertinente si se refiere y se contiene en el aquí y ahora de sus actores. Como he dicho, la escuela de hoy, viendo al futuro, debe preparar a los jóvenes de hoy. Pretender escuelas aisladas de sus propios contextos - esto es, familias y comunidades- es hacer del proceso de enseñanza-aprendizaje un proceso no pertinente, $y$, consecuentemente, no útil, no real.

Por ello, la religación de la escuela con las propias familias y con las comunidades mismas es algo necesario, porque solo así se inserta dentro de su propio entorno cultural, y, por supuesto, abierta a la mirada del contexto mundial, sabrá ella qué es lo que debe ser enseñado y para qué debe ser enseñado.

Una escuela desvinculada de su contexto provoca peligrosamente un ignorar los valores de la propia cultura, a riesgo de invertirlos en vez de confirmarlos y practicarlos. Ello pudiera llevar a constituir pueblos perversos, siguiendo a Ortega y Gasset cuando dice que aquellos pueblos que invierten sus valores se convierten en eso, en pueblos perversos; juicio que estamos prestos a confirmar antes que a rebatir. Reafirmamos, entonces, que "la enseñanza solo es enseñanza de calidad si es una enseñanza pertinente".

El dar la responsabilidad de la educación sólo a los maestros, y en determinado grado, a las familias, ya no es un concepto acorde con la realidad. No es posible descargar tamaña responsabilidad en tan reducido conjunto de actores. Hay que partir entonces de que la escuela es ella y su entorno, es ella y su historia, es ella y su cultura.

Asumimos, pues, el presupuesto - que nos parece incuestionable - de que "para educar a un niño hace falta, no una escuela sino la sociedad entera".

\section{4) Bases conceptuales en las que se sustenta el modelo.}

Es necesario que un modelo educativo se sustente y sostenga en una filosofía de la educación propia y arraigada en las necesidades de su misma población. En nuestro caso, esta filosofía antepone el formar al informar. Debemos formar a nuestros niños y a nuestros jóvenes. La información es una necesidad solo justificada si se ha logrado lo anterior. Entendemos esta filosofía en la forma siguiente. Debemos:

1) Formar dentro de un marco de auténtico sentido nacional, incorporando adecuadamente y con la ponderación correspondiente en los programas de estudio un fuerte componente histórico-cultural con el cual se asegure de que todo salvadoreño reciba, en la escuela, una suficiente y adecuada formación que le proporcione los elementos necesarios para sentir y vivir en ple- 
nitud su pertenencia y su identidad como tal. Concretamente, un fuerte y sostenido estudio de la historia, de la cultura, de la identidad nacional y, especialmente, del lenguaje.

2) Formar dentro de un marco de auténtico sentido humano, incorporando adecuadamente y con la ponderación correspondiente en los programas de estudio un fuerte componente de formación humanística, con el cual se asegure que todo salvadoreño reciba en la escuela una suficiente y adecuada formación, que le proporcione los elementos necesarios para cultivar sus necesidades espirituales más íntimas y para desenvolverse dentro de los núcleos culturales del mundo sin menoscabo de su propio origen y de su propio ser. Concretamente, una fuerte y sostenida formación filosófica, axiológica, ética y estética, y así, la introyección de un marco valorativo originado en la vivencia existencial misma.

3) Formar dentro de un contexto mundial en el que el componente científico y tecnológico se proyecta claramente como uno de los hilos conductores del futuro y del desarrollo, con el cual se asegure que todo salvadoreño reciba en la escuela una suficiente y adecuada formación científica, que le proporcione los elementos necesarios para incorporarse y participar plenamente en un mundo marcado fuertemente por la necesidad cognoscitiva e innovadora de la ciencia. Concretamente, una fuerte y sostenida formación científica con énfasis claro en el estudio de la naturaleza, del mundo físico en que vivimos, de las ciencias físico-químico-biológicas, y con una adecuada y suficiente capacitación matemática. Habrá que propender, en la escuela, a inculcar el espíritu de observación, de investigación y, en general, el uso del método científico como forma adecuada de estudio y análisis.

4) Entonces, y solo entonces, deberá la escuela responder a la necesidad de informar y de mantenerse actualizada en cuanto a los avances del desarrollo tecnológico y económico mundiales, con el objeto de que la escuela ayude a ubicar correctamente a todo salvadoreño dentro del contexto de dicho desarrollo y, a la vez, lo capacite para poder interpretarlo y ajustarse adecuadamente, sostenido por el fuerte andamiaje de su formación cultural, humanista y científica recibida, a las tendencias del desarrollo mundial.
5) En otras palabras, un adecuado equilibrio de los dos componentes fundamentales de todo proceso educativo: la formativa y la informativa. Se trata entonces, y en ese orden, de formar e informar: formar en la historia, en la cultura, en el humanismo, en la ciencia; informar en la técnica y en la economía.

6) la solución es supeditar la conformación de un modelo educativo que sea un medio, una herramienta para el desarrollo económico; y, más aún, para un modelo económico determinado, a la conformación de un modelo educativo que sea un medio para el desarrollo integral del hombre, dentro del cual, por supuesto, el bienestar económico será siempre uno de los componentes esenciales, esto es, hacer de la educación un fin en sí mismo y no un medio al servicio del modelo económico.

7) Lo anterior será posible si el Estado reconoce y define Ios planos estructurales del hombre en el orden correcto de prioridades. El plano cultural y educativo en primer orden, esto es, el plano de las creencias fácticas, en qué cosas reales e ideales se cree y no; es también el plano de los valores, el de qué cosas reales o ideales se consideran buenas o malas, y cómo; es también el plano de lo normativo, el de qué conductas deben ser consideradas como obligatorias o no, y cómo; y es también el plano de lo simbólico, de los significados y de las expresiones del lenguaje. En los hombres y en los pueblos auténticos, la cultura y la educación constituyen siempre el plano estructural de mayor jerarquía y a partir del cual se generan los otros. El plano de la participación, en el cual aparecen los actores, los status y los papeles, y que es, precisamente, el plano de la familia, como segunda prioridad. Luego, y solo entonces, el plano político. Y finalmente, y sólo entonces, el plano económico. Solo así ordenados los planos estructurales del hombre salvadoreño, nuestro pueblo podrá ser auténtico. Invertir ese orden jerárquico es entrar en formas alienantes y admitir de alguna manera la posibilidad de conformar modelos sociales de sojuzgamiento y dependencia, expresiones estas — como se sabe — las más dolorosas de las formas de negación del hombre $y$ de los pueblos en su justa y precisa autenticidad. El proceso educativo, en este proyecto de cambio, debe tender entonces a eso: A definir correctamente los planos estructurales del hombre salvadoreño en ese orden: el plano de la cultura y de la educación; el plano 
de la participación; el plano político; y finalmente, el plano económico. Dicho lo anterior en el orden de las instituciones: sociedad, familia, Estado y economía. El proyecto nacional debe ver, entonces, a la educación y a la cultura como las condiciones primeras de todo proyecto de nación, su punto de partida, su hilo conductor.

8) La filosofía de la educación, dentro de un programa de transformación de la educación en el país que busque realmente colocar fuertes y auténticos cimientos culturales en el pueblo, debe confirmar y autosustentar el reconocimiento, como entes privilegiados de la nación, a: la persona humana, y especialmente en ella, los niños, los ancianos y los maestros; las instituciones que conforman nuestro sustento cultural e histórico; y el entorno natural, del cual la patria se nutre y sin el cual la vida no sería posible. Se debe apostar, firme y conscientemente, a que todo salvadoreño debe actuar, en su existencia concreta, pensando en los hombres del pasado y del futuro, así como en sus mentores. De la misma manera, que la historia y la cultura deben ser auténticos motivos de orgullo nacional. Y finalmente, que el más rico de los patrimonios de un pueblo es su entorno natural, y que, por lo tanto, la tierra, el aire, al agua, los bosques, la flora y la fauna deben ser preservados y defendidos aun a costa del mayor de los sacrificios. El proyecto afirma, como base filosófica, que es un compromiso ineludible privilegiar a los niños, a Ios ancianos y a los maestros, a nuestras instituciones culturales e históricas, y a nuestro entorno natural.

Aquí, un imperativo categórico: la base de un auténtico proceso educativo reside en reconocer $y$ admitir: A la cultura como base del desarrollo; a la familia y a la comunidad como sustento de organización social; y a la política y a la economía como medios para lograr lo anterior.

\section{5) El sistema integrado de la "Escuela Inclusiva de Tiempo Pleno"}

Optar es —pienso yo- una 'situación límite' del hombre, recogiendo esa tremenda categoría filosófica de Karl Jaspers, como lo son también la muerte, la angustia, la duda. Es un no-poder-no. El hombre, así como no-puede-no- morir, o no-puede-no-dudar, también un no-puede-no-optar. Y el país no-puede-no-optar ante esta disyuntiva educativa, opción esta esencial; porque la educación es de las ya pocas esencialidades que le quedan al hombre, dado que el hombre es precisamente persona porque, sí, ciertamente, es espíritu, —como diría San Agustín-, pero también es opción —como diría el existencialismo—.

El "Sistema Integrado de la 'Escuela Inclusiva de Tiempo Pleno' " busca tres objetivos: calidad, universalidad y pertinencia, que en el fondo son uno solo; y lo hace a través de siete estrategias: 1) dignificar y desarrollar profesionalmente al magisterio nacional; 2) desarrollar un currículo pertinente y aprendizajes significativos; 3 ) formar permanentemente a la población joven y adulta; 4) asegurar equidad en el acceso y en la permanencia en el sistema educativo; 5) fortalecer la gestión institucional y curricular; 6) desarrollar investigación, ciencia y tecnología como medios para acceder a una sociedad del conocimiento y no a una sociedad de la información, y 7) fortalecer la educación superior. No debe buscarse una educación que no sea pertinente, porque ello niega de hecho la calidad; ni debe continuarse con ese concepto equivocado de cobertura como sinónimo de masificación de la mala escuela, sino debe buscarse un concepto de universalidad que haga justicia al niño y al joven desamparado, pero que a su vez los coloque en similares condiciones que los amparados. Este es un cambio grueso en el concepto. No debemos tener escuelas especiales en las que se margine y diferencie a las personas, sino escuelas en las que se integren todos con iguales oportunidades, aunque reconociendo a cada quien su propia circunstancia. Ese es mi concepto de inclusión: integrar los cuatro actores del proceso educativo: alumnos, maestros, familia y comunidad, pero con papeles claros en cada quien, con responsabilidades establecidas y diferenciadas, y no en una mezcla amorfa y confusa en la que cada quien hace lo que al otro le corresponde sin tener facultades y posibilidades para hacerlo bien. Deben desarrollarse aulas integradas en las que se transmita, pero que también se desarrolle, conocimiento. Ya no el aula de primer grado, o de cuarto grado, o de octavo grado; ya no el maestro de primer grado, o de cuarto grado, o de octavo grado; ahora es el aula especializada, el aula de matemática, de ciencias, de música, de historia, en la que se integran todos; niños de diferentes niveles ante grupos docentes capacitados para enseñar a todos los niveles, con bibliotecas 
de aula para cada especialidad, y con recursos pedagógicos idóneos a cada especialidad. El 'tiempo pleno' no significa más tiempo del niño y del maestro dentro del recinto físico de la escuela, sino más tiempo de la escuela en la mente del niño, del maestro, de la familia y de la comunidad, dondequiera que estos se encuentren.

Lamentablemente, el concepto de escuela inclusiva de tiempo pleno está siendo penosamente desnaturalizado, utilizándose más para otros fines que para los que fue pensado; y de la misma forma el "Plan Social-Educativo 2009-2014 'Vamos a la Escuela' ". ¿Por qué se está dando tan lamentable situación? Porque —como he dicho al principio- la educación no es, en la realidad, una prioridad para el Gobierno, sino un elemento político-partidista y de desarrollo y control territorial. Mientras eso no se corrija, la educación en El Salvador será un elemento diferenciador más que integrador; una causa de brecha social; un peligroso instrumento de dominio.

Como en la educación, también en otros campos y ámbitos del hacer nacional no hemos podido comprender esa urgente verdad que nos hiciera ver el gran filósofo neotomista mexicano Salomón Rahaim:

"Estamos para un diálogo transcendental y no para escarceos de mero lujo". 